Article

\title{
Biological Evaluation and Molecular Docking with In Silico Physicochemical, Pharmacokinetic and Toxicity Prediction of Pyrazolo[1,5-a]pyrimidines
}

\author{
Ahmed M. Naglah 1,2®) Ahmed A. Askar ${ }^{3, *(1)}$, Ashraf S. Hassan ${ }^{4, *}$, Tamer K. Khatab ${ }^{4}$, \\ Mohamed A. Al-Omar ${ }^{1}(\mathbb{D})$ and Mashooq A. Bhat ${ }^{5}(\mathbb{D}$ \\ 1 Department of Pharmaceutical Chemistry, Drug Exploration and Development Chair (DEDC), College of \\ Pharmacy, King Saud University, Riyadh 11451, Saudi Arabia; anaglah@ksu.edu.sa (A.M.N.); \\ malomar1@ksu.edu.sa (M.A.A.-O.) \\ 2 Peptide Chemistry Department, National Research Centre, Dokki, Cairo 12622, Egypt \\ 3 Botany and Microbiology Department, Faculty of Science (Boys), Al-Azhar University, Cairo, Egypt \\ 4 Organometallic and Organometalloid Chemistry Department, National Research Centre, Dokki, Cairo 12622, \\ Egypt; tamer_khatab@hotmail.com \\ 5 Department of Pharmaceutical Chemistry, College of Pharmacy, King Saud University, Riyadh 11451, \\ Saudi Arabia; mabhat@ksu.edu.sa \\ * Correspondence: drahmed_askar@azhar.edu.eg (A.A.A.); ashraf_salmoon@yahoo.com (A.S.H.); \\ Tel.: +20-101-081-5102 (A.A.A.); +20-100-664-5444 (A.S.H.)
}

Academic Editors: Anna Carbone and Fabio Bertozzi

Received: 28 February 2020; Accepted: 18 March 2020; Published: 21 March 2020

\begin{abstract}
Pyrazolo[1,5-a]pyrimidines $5 \mathbf{a}-\mathbf{c}, \mathbf{9 a}-\mathbf{c}$ and $\mathbf{1 3} \mathbf{a}-\mathbf{i}$ were synthesized for evaluation of their in vitro antimicrobial properties against some microorganisms and their immunomodulatory activity. The biological activities of pyrazolo[1,5-a]pyrimidines showed that the pyrazolo[1,5- $a$ ]pyrimidines $(\mathbf{5 c}$, 9a, 9c, 13a, 13c, 13d, 13e and 13h) displayed promising antimicrobial and immunomodulatory activities. Studying the in silico predicted physicochemical, pharmacokinetic, ADMET and drug-likeness properties for the pyrazolo[1,5-a]pyrimidines $5 \mathbf{a}-\mathbf{c}, \mathbf{9 a}-\mathbf{c}$ and $\mathbf{1 3} \mathbf{a}-\mathbf{i}$ confirmed that most of the compounds (i) were within the range set by Lipinski's rule of five, (ii) show higher gastrointestinal absorption and inhibition of some CYP isoforms, and (iii) have a carcinogenicity test that was predicted as negative and hERG test that presented medium risk. Moreover, the molecular docking study demonstrated that the compounds 5c, 9a, 9c, 13a, 13c, 13d, 13e and 13h are potent inhibitors of 14-alpha demethylase, transpeptidase and alkaline phosphatase enzymes. This study could be valuable in the discovery of a new series of drugs.
\end{abstract}

Keywords: pyrazolo[1,5-a]pyrimidine; antimicrobial; immunomodulatory; Lipinski's rule; molecular docking; enzyme inhibitor

\section{Introduction}

Treatment of infectious diseases remains a worldwide problem because of the increasing multi-drug resistance caused by human pathogenic microbes. Therefore, the design of new compounds acting as antimicrobial agents is an essential approach to overcome the problem of drug resistance [1].

In recent years, pyrazolo [1,5-a]pyrimidine derivatives have received a special interest due to their diverse biological and pharmacological activities including DNA binding and anti-tubercular, antioxidant, antibacterial and anticancer activities [2-8]. Among these pyrazolo[1,5-a]pyrimidine derivatives, compound A showed potent antibacterial activity against Escherichia coli and Bacillus subtilis when compared to standard drug (Penicillin) [9]. Compound B displayed excellent antifungal activity against Fusarium oxysporum when compared with Amphotericin B [10]. Compound C exhibited 
remarkably high antimicrobial activities against Klebsiella pneumoniae and Fusarium oxysporum [11]. Furthermore, the pyrazolo[1,5-a]pyrimidine moiety is found in some marketed drugs with different biological activities such as: Zaleplon, which is a sedative-hypnotic used to treat insomnia; Ocinaplon, which is an anxiolytic drug; and Dinaciclib (SCH-727965), a cyclin-dependent kinases (CDKs) inhibitor that it is being evaluated in clinical trials for various cancer indications [12,13] (Figure 1).

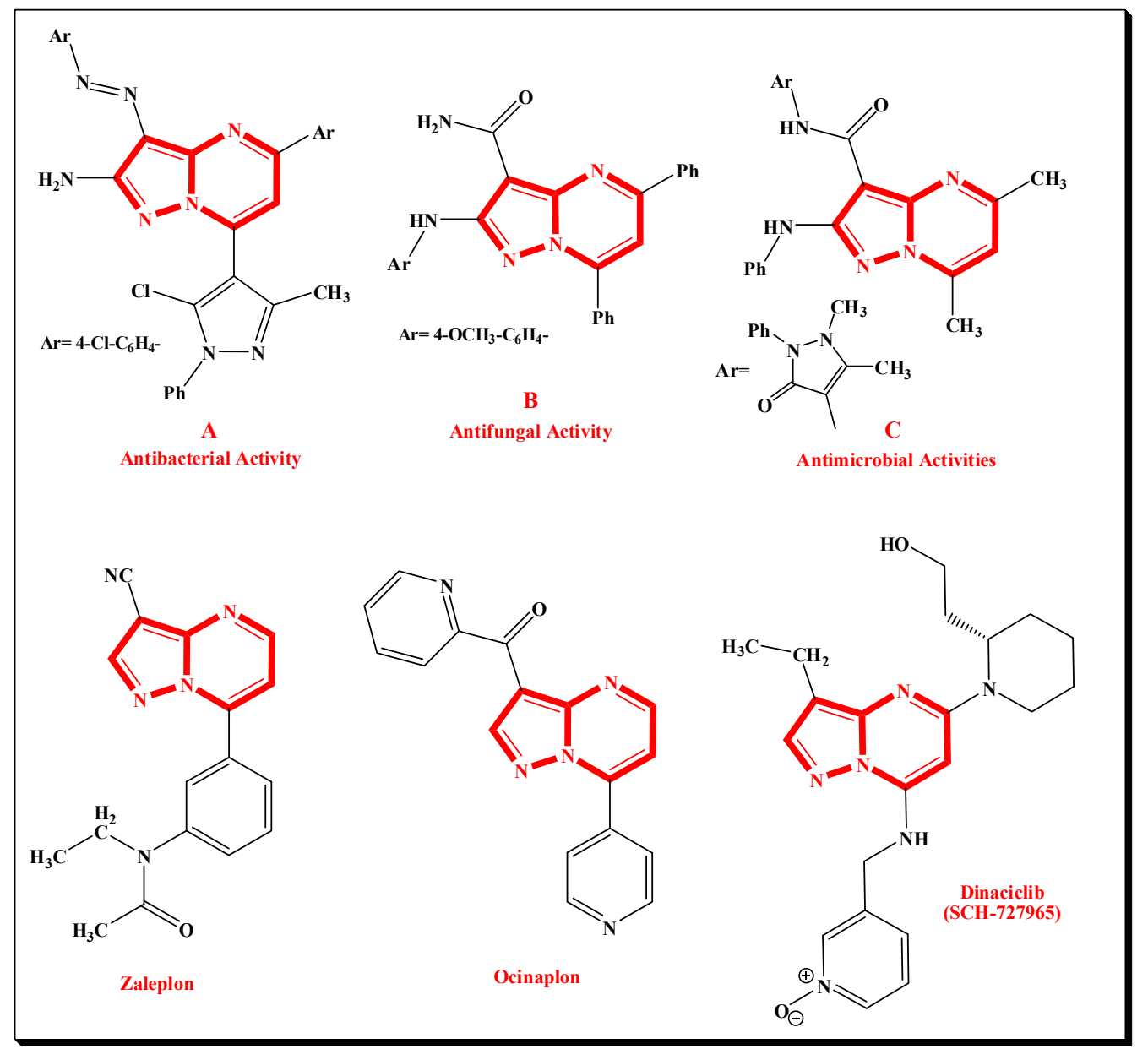

Figure 1. Examples of biological activities of pyrazolo[1,5-a]pyrimidines and the structures of some drugs.

Based on the above facts and in continuation of our target [14-25], the purpose of this paper is to evaluate and study the antimicrobial activity \{inhibition zone (IZ), the minimum inhibitory concentration (MIC), the minimum bactericidal concentration (MBC) and the minimum fungicidal concentration (MFC) \}, the immunomodulatory activity, the physicochemical, pharmacokinetic, and drug-likeness properties, the structure-activity relationship and the molecular docking of pyrazolo [1,5-a]pyrimidine derivatives (e.g., 5,7-dimethylpyrazolo[1,5-a]pyrimidines 5a-c, 5,7-dihydroxypyrazolo

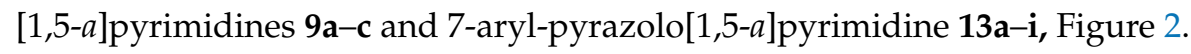




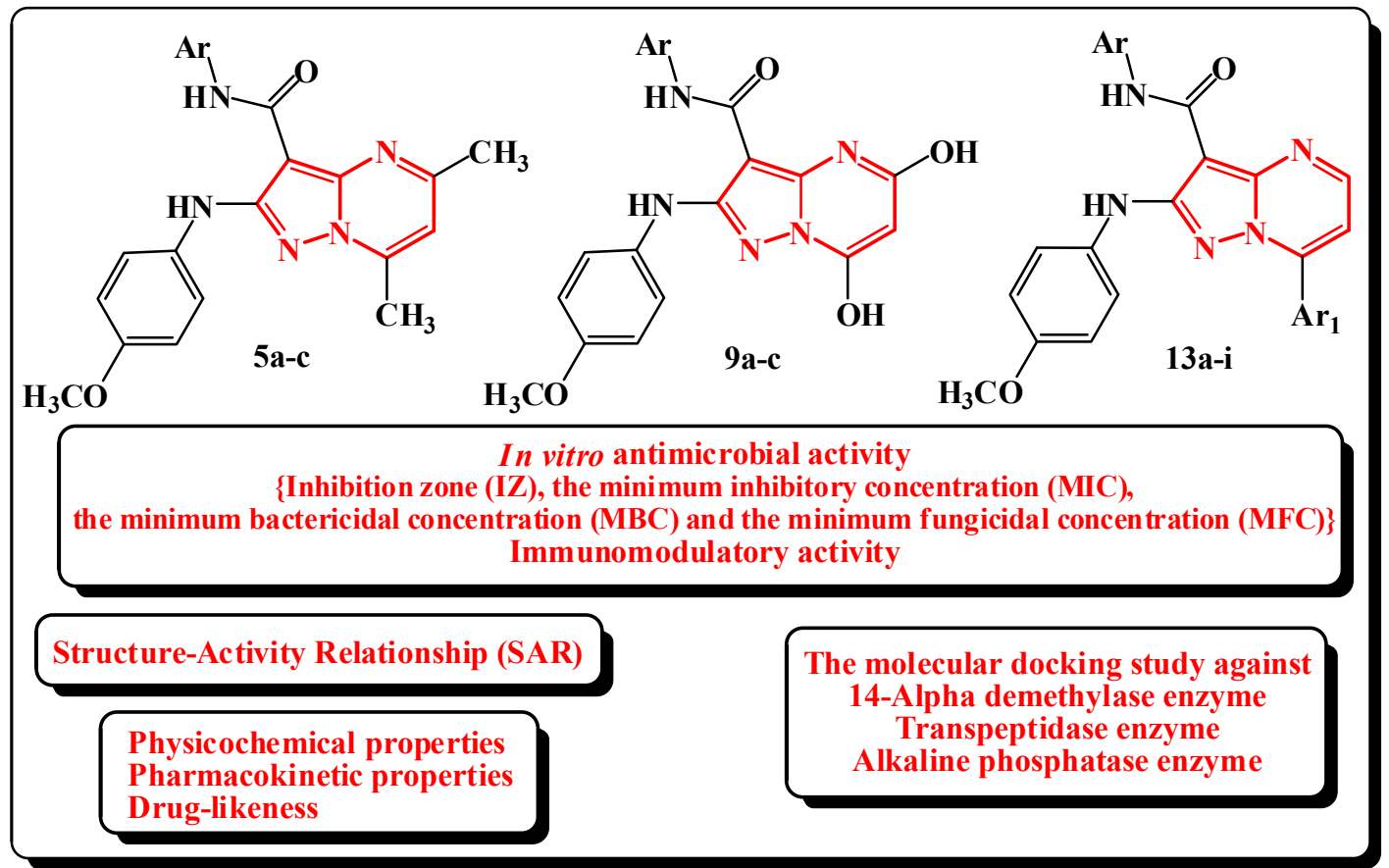

Figure 2. Structure of the target pyrazolo[1,5-a]pyrimidines (5a-c, $9 \mathbf{a}-\mathbf{c}$ and $\mathbf{1 3 a}-\mathbf{i})$ and their studies.

\section{Results and Discussion}

\subsection{Chemistry}

The starting materials, 5-amino- $\mathrm{N}$-aryl- $1 \mathrm{H}$-pyrazole-4-carboxamides $\mathbf{1 a}-\mathbf{c}$, were prepared according to our previous work [26]. The syntheses of the targets, 5,7-dimethylpyrazolo[1,5- $a$ ]pyrimidines 5a-c, 5,7-dihydroxypyrazolo[1,5-a]pyrimidines 9a-c and 7-aryl-pyrazolo[1,5-a]pyrimidines 13a-i, are illustrated in Schemes 1 and 2.

Compounds 1a-c were reacted with acetylacetone (2) or diethyl malonate (6) in refluxing glacial acetic acid to afford the corresponding 5,7-dimethylpyrazolo[1,5-a]pyrimidines 5a-c or 5,7-dihydroxypyrazolo[1,5-a]pyrimidines 9a-c (enol-form), respectively (Scheme 1).

The target compounds, 7-aryl-pyrazolo[1,5-a]pyrimidine 13a-i, were prepared via the reaction of compounds 1a-c with 1-(aryl)-3-(dimethylamino)prop-2-en-1-ones 10a-c in glacial $\mathrm{CH}_{3} \mathrm{COOH}$ (Scheme 2).

\subsection{Biological Evaluation}

\subsubsection{In Vitro Antimicrobial Evaluation}

The antimicrobial activities inhibition zone (IZ, $\mathrm{mm} \pm$ standard deviation) of the pyrazolo[1,5- $a$ ] pyrimidines $(\mathbf{5} \mathbf{a}-\mathbf{c}, \mathbf{9} \mathbf{9}-\mathbf{c}$ and $\mathbf{1 3 a}-\mathbf{i})$ were evaluated using the agar plate diffusion method $[27,28]$. The results of the inhibition zone are listed in Table 1. 


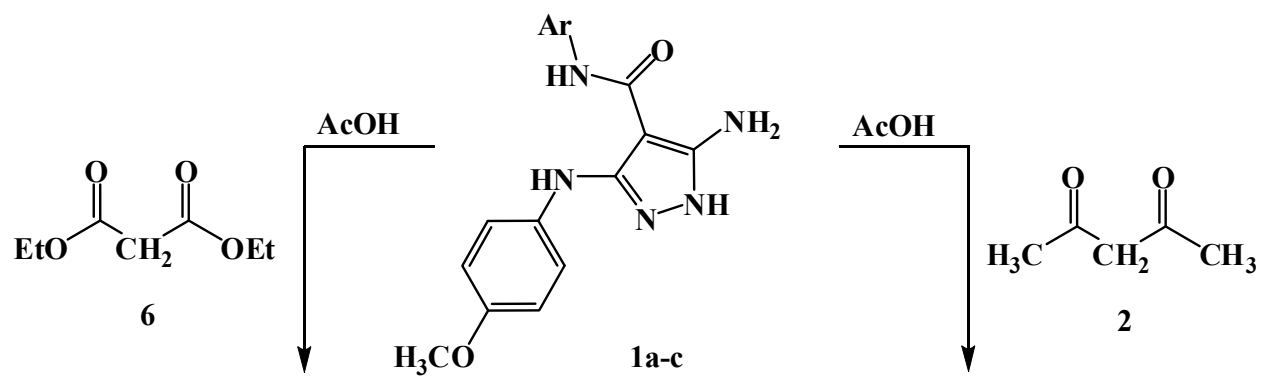<smiles>COc1ccc(Nc2n[nH]c(NC(=O)CC(=O)O)c2C(=O)O)cc1</smiles>
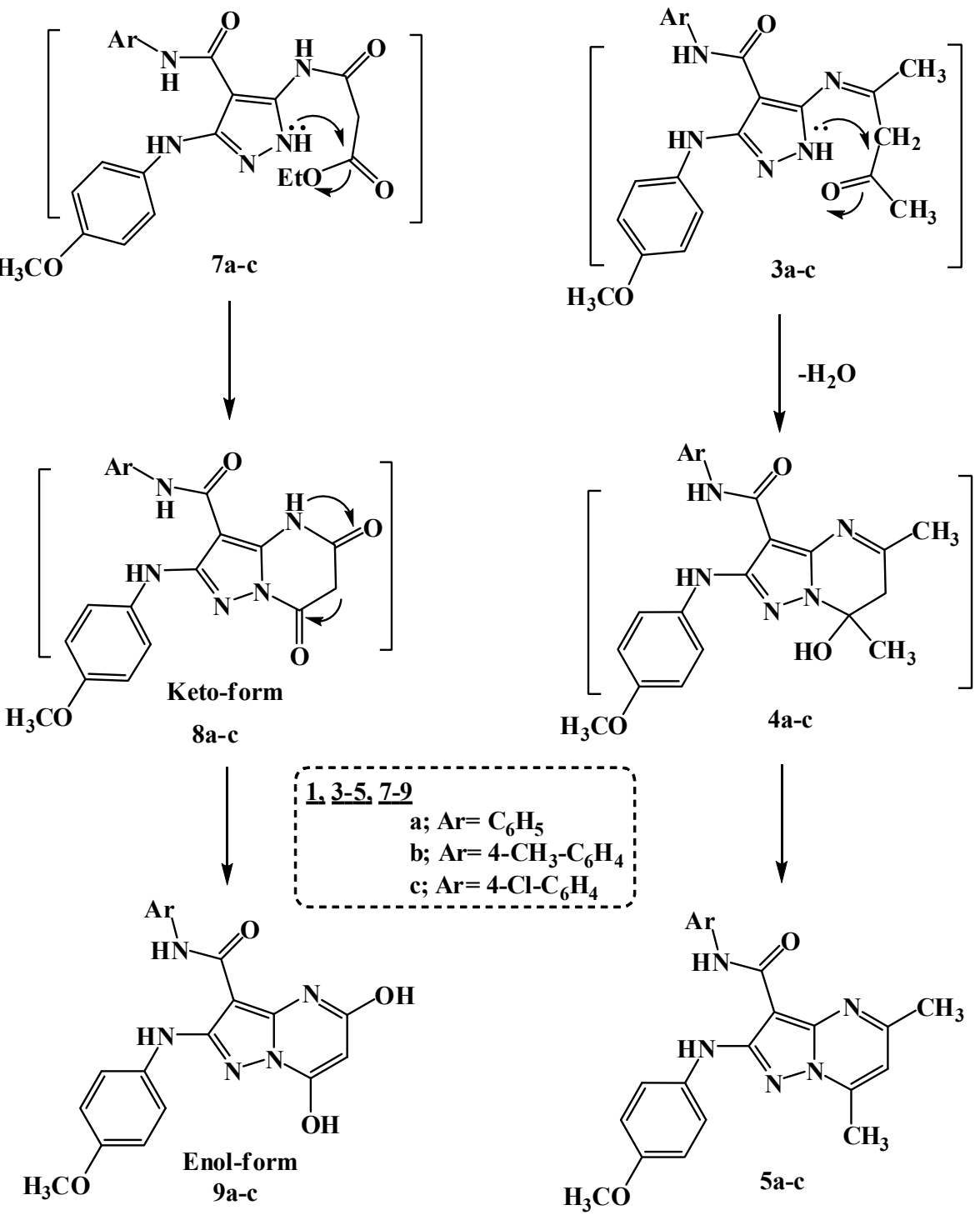

Scheme 1. Synthesis of pyrazolo[1,5-a]pyrimidines $\mathbf{5 a - c}$ and $\mathbf{9 a - c}$. 

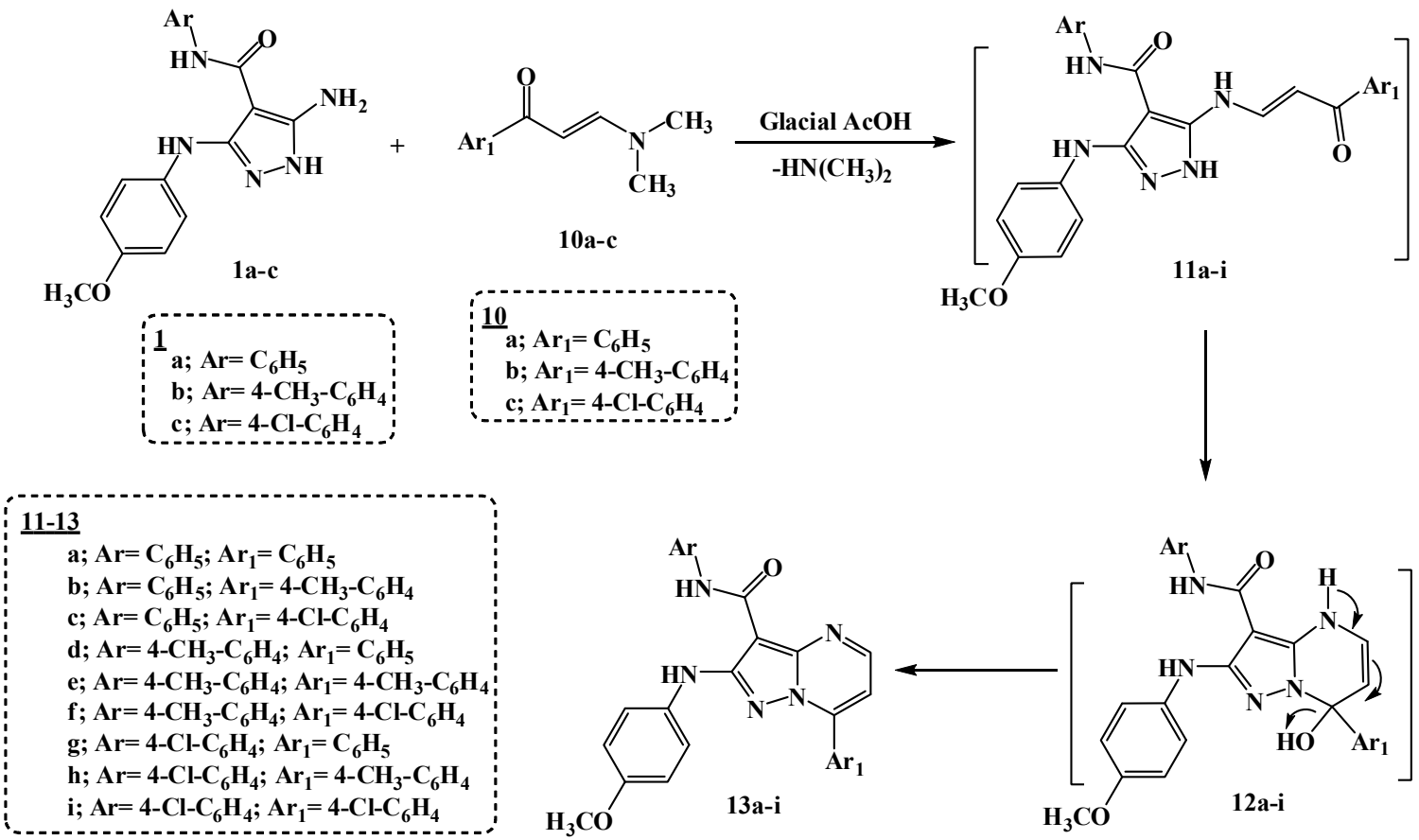

Scheme 2. Synthesis of 7-aryl-pyrazolo[1,5-a]pyrimidines 13a-i.

Table 1. Antimicrobial activities of the pyrazolo[1,5-a]pyrimidines (5a-c, 9a-c and 13a-i) and the reference drugs expressed as inhibition zone (IZ, $\mathrm{mm} \pm$ standard deviation).

\begin{tabular}{cccccccccc}
\hline \multirow{2}{*}{ Comp. } & \multicolumn{3}{c}{ Gram-Positive Bacteria } & \multicolumn{3}{c}{ Gram-Negative Bacteria } & \multicolumn{3}{c}{ Fungi } \\
\cline { 2 - 10 } & $\mathbf{B c}$ & $\mathbf{S a}$ & $\mathbf{E f}$ & $\mathbf{E c}$ & $\mathbf{P a}$ & St & Ca & Fo & Ab \\
\hline $\mathbf{5 a}$ & $11 \pm 0.61$ & $20 \pm 0.25$ & $13 \pm 0.23$ & $13 \pm 0.34$ & NA & NA & NA & NA & NA \\
$\mathbf{5 b}$ & $14 \pm 0.54$ & $11 \pm 0.84$ & $13 \pm 0.23$ & $10 \pm 0.62$ & NA & NA & $12 \pm 0.63$ & $7 \pm 0.34$ & NA \\
$\mathbf{5 c}$ & $19 \pm 0.14$ & $21 \pm 0.49$ & $22 \pm 0.68$ & $18 \pm 0.24$ & $19 \pm 0.43$ & $18 \pm 0.39$ & $17 \pm 0.33$ & $12 \pm 0.95$ & $13 \pm 0.95$ \\
$\mathbf{9 a}$ & $23 \pm 0.18$ & $19 \pm 0.37$ & $16 \pm 0.83$ & $14 \pm 0.21$ & $16 \pm 0.33$ & $16 \pm 0.77$ & $15 \pm 0.25$ & $13 \pm 0.39$ & $16 \pm 0.79$ \\
$\mathbf{9 b}$ & $10 \pm 0.24$ & $15 \pm 0.15$ & NA & $18 \pm 0.18$ & NA & $14 \pm 0.48$ & NA & $10 \pm 0.28$ & NA \\
$\mathbf{9 c}$ & $16 \pm 0.78$ & $21 \pm 0.24$ & $25 \pm 0.23$ & $17 \pm 0.84$ & $15 \pm 0.34$ & $18 \pm 0.18$ & $19 \pm 0.24$ & $16 \pm 0.78$ & $13 \pm 0.43$ \\
$\mathbf{1 3 a}$ & $13 \pm 0.11$ & $16 \pm 0.34$ & $13 \pm 0.23$ & $15 \pm 0.23$ & $14 \pm 0.78$ & $16 \pm 0.33$ & $13 \pm 0.65$ & $14 \pm 0.11$ & $11 \pm 0.42$ \\
$\mathbf{1 3 b}$ & $9 \pm 0.37$ & NA & NA & $12 \pm 0.62$ & NA & NA & $12 \pm 0.46$ & $14 \pm 0.22$ & NA \\
$\mathbf{1 3 c}$ & $17 \pm 0.23$ & $10 \pm 0.47$ & $13 \pm 0.23$ & $15 \pm 0.45$ & $12 \pm 0.61$ & $14 \pm 0.47$ & $14 \pm 0.23$ & $11 \pm 0.22$ & $10 \pm 0.32$ \\
$\mathbf{1 3 d}$ & $14 \pm 0.23$ & $18 \pm 0.87$ & $16 \pm 0.23$ & $19 \pm 0.14$ & $17 \pm 0.46$ & $17 \pm 0.76$ & $16 \pm 0.81$ & $15 \pm 0.66$ & $13 \pm 0.33$ \\
$\mathbf{1 3 e}$ & $17 \pm 0.32$ & $17 \pm 0.74$ & $23 \pm 0.21$ & $16 \pm 0.96$ & $15 \pm 0.77$ & $13 \pm 0.98$ & $18 \pm 0.11$ & $13 \pm 0.44$ & $12 \pm 0.32$ \\
$\mathbf{1 3 f}$ & $10 \pm 0.14$ & $15 \pm 0.64$ & NA & $11 \pm 0.12$ & NA & $13 \pm 0.32$ & $12 \pm 0.44$ & $10 \pm 0.48$ & NA \\
$\mathbf{1 3 g}$ & $12 \pm 0.47$ & $8 \pm 0.2$ & $13 \pm 0.23$ & $11 \pm 0.27$ & NA & NA & NA & NA & NA \\
$\mathbf{1 3 h}$ & $20 \pm 0.34$ & $18 \pm 0.16$ & $20 \pm 0.13$ & $17 \pm 0.15$ & $18 \pm 0.12$ & $16 \pm 0.85$ & $20 \pm 0.26$ & $15 \pm 0.76$ & $14 \pm 0.12$ \\
$\mathbf{1 3 i}$ & NA & NA & NA & $13 \pm 0.85$ & NA & $11 \pm 0.12$ & $15 \pm 0.56$ & $12 \pm 0.15$ & NA \\
ST1 & $22 \pm 0.42$ & $24 \pm 0.61$ & $25 \pm 0.45$ & $23 \pm 0.33$ & $20 \pm 0.55$ & $22 \pm 0.18$ & NA & NA & NA \\
ST2 & NA & NA & NA & NA & NA & NA & $15 \pm 0.2$ & $20 \pm 0.32$ & $18 \pm 0.2$ \\
\hline
\end{tabular}

Gram-positive bacteria: Bacillus cereus (ATCC14579, Bc), Staphylococcus aureus (ATCC 29213, Sa) and Enterococcus faecalis (ATCC 29212, Ef). Gram-negative bacteria: Escherichia coli (ATCC 25922, Ec) Pseudomonas aeruginosa (ATCC 27853, Pa) and Salmonella typhi (ATCC 6539, St). Fungi: Candida albicans (ATCC 10231, Ca), Fusarium oxysporum (RCMB 008002, Fo) and Aspergillus brasiliensis (ATCC 16404, Ab). ST1: Amoxicillin/Clavulanic acid as antibacterial standard; ST2: Nystatin as antifungal standard. NA: No activity.

From the results (Table 1), we can deduce that eight compounds (5c, 9a, 9c, 13a, 13c, 13d, 13e and 13h) displayed broad-spectrum in vitro antimicrobial activities against the bacteria and fungi used in this study. Therefore, the minimum inhibitory concentration (MIC, $\mu \mathrm{g} / \mathrm{mL}$ ), the minimum bactericidal concentration (MBC, $\mu \mathrm{g} / \mathrm{mL}$ ) and the minimum fungicidal concentration (MFC, $\mu \mathrm{g} / \mathrm{mL}$ ) of the most potent pyrazolo[1,5-a]pyrimidines $(5 \mathbf{c}, 9 \mathbf{a}, 9 \mathbf{c}, 13 \mathbf{a}, \mathbf{1 3 c}, \mathbf{1 3 d}, \mathbf{1 3 e}$ and $\mathbf{1 3 h})$ were determined by the 
conventional technique termed paper disk diffusion [29-31] and the results of MIC, MBC and MFC are listed in Table 2.

Table 2. The minimum inhibitory concentration (MIC, $\mu \mathrm{g} / \mathrm{mL}$ ), the minimum bactericidal concentration $(\mathrm{MBC}, \mu \mathrm{g} / \mathrm{mL})$ and the minimum fungicidal concentration $(\mathrm{MFC}, \mu \mathrm{g} / \mathrm{mL})$ of the pyrazolo[1,5-a]pyrimidines $(5 \mathbf{a}-\mathbf{c}, \mathbf{9 a}-\mathbf{c}$ and $\mathbf{1 3} \mathbf{a}-\mathbf{i})$ and the reference drugs.

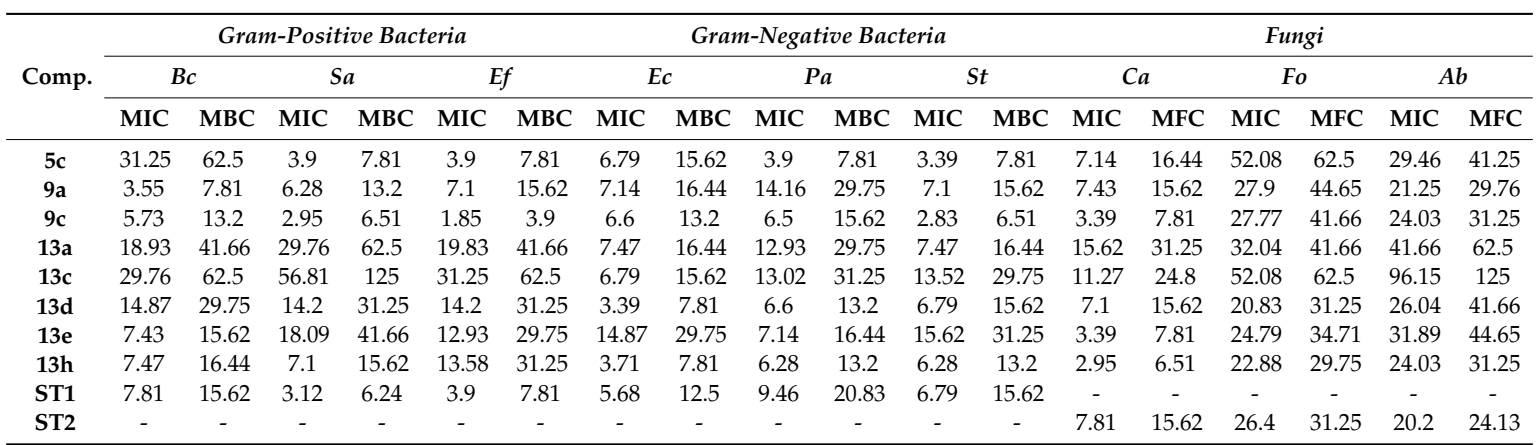

Gram-positive bacteria: Bacillus cereus (ATCC14579, Bc), Staphylococcus aureus (ATCC 29213, Sa) and Enterococcus faecalis (ATCC 29212, Ef). Gram-negative bacteria: Escherichia coli (ATCC 25922, Ec), Pseudomonas aeruginosa (ATCC 27853, Pa) and Salmonella typhi (ATCC 6539, St). Fungi: Candida albicans (ATCC 10231, Ca), Fusarium oxysporum (RCMB 008002, Fo) and Aspergillus brasiliensis (ATCC 16404, Ab). ST1: Amoxicillin/Clavulanic acid as antibacterial standard; ST2: Nystatin as antifungal standard.

From the result of MIC values, we could see that in the case of Bacillus cereus (Bc) bacteria, pyrazolopyrimidine 9a $(\mathrm{MIC}=3.55 \mu \mathrm{g} / \mathrm{mL})$ was 1-fold more potent than Amoxicillin/Clavulanic acid $(\mathrm{MIC}=7.81 \mu \mathrm{g} / \mathrm{mL})$, while compounds 9c $(\mathrm{MIC}=5.73 \mu \mathrm{g} / \mathrm{mL}), 13 \mathbf{e}(\mathrm{MIC}=7.43 \mu \mathrm{g} / \mathrm{mL})$ and $13 \mathrm{~h}(\mathrm{MIC}$ $=7.47 \mu \mathrm{g} / \mathrm{mL}$ ) were equipotent to the reference drug (Amoxicillin/Clavulanic acid $(\mathrm{MIC}=7.81 \mu \mathrm{g} / \mathrm{mL})$ ).

In the case of Staphylococcus aureus (Sa) bacteria, the two compounds $5 \mathrm{c}(\mathrm{MIC}=3.9 \mu \mathrm{g} / \mathrm{mL})$ and $9 \mathrm{c}$ $(\mathrm{MIC}=2.95 \mu \mathrm{g} / \mathrm{mL}$ ) were equipotent to Amoxicillin/Clavulanic acid $(\mathrm{MIC}=3.12 \mu \mathrm{g} / \mathrm{mL})$.

In the case of Enterococcus faecalis (Ef) bacteria, pyrazolopyrimidine $9 \mathrm{c}$ (MIC $=1.85 \mu \mathrm{g} / \mathrm{mL}$ vs. MIC $=3.9 \mu \mathrm{g} / \mathrm{mL})$ was 1 -fold more potent than the drug used, while compound $5 \mathrm{c}(\mathrm{MIC}=3.9 \mu \mathrm{g} / \mathrm{mL})$ was equipotent to Amoxicillin/Clavulanic acid (MIC $=3.9 \mu \mathrm{g} / \mathrm{mL}$ ).

The two compounds $13 \mathrm{~d}(\mathrm{MIC}=3.39 \mu \mathrm{g} / \mathrm{mL})$ and $\mathbf{1 3 h}(\mathrm{MIC}=3.71 \mu \mathrm{g} / \mathrm{mL})$ were 1 -fold more potent than the Amoxicillin/Clavulanic acid (MIC $=5.68 \mu \mathrm{g} / \mathrm{mL}$ ) in the case of Escherichia coli (Ec) bacteria.

The five compounds $5 \mathrm{c}(\mathrm{MIC}=3.9 \mu \mathrm{g} / \mathrm{mL}), 9 \mathrm{c}(\mathrm{MIC}=6.5 \mu \mathrm{g} / \mathrm{mL}), \mathbf{1 3 d}(\mathrm{MIC}=6.6 \mu \mathrm{g} / \mathrm{mL}), \mathbf{1 3 e}(\mathrm{MIC}$ $=7.14 \mu \mathrm{g} / \mathrm{mL})$ and $13 \mathrm{~h}(\mathrm{MIC}=6.28 \mu \mathrm{g} / \mathrm{mL})$ were more potent than the drug used (Amoxicillin/Clavulanic acid $(\mathrm{MIC}=9.46 \mu \mathrm{g} / \mathrm{mL})$ ) in the case of Pseudomonas aeruginosa $(\mathrm{Pa})$ bacteria.

For the Salmonella typhi $(\mathrm{St})$ bacteria, the compounds $5 \mathrm{c}(\mathrm{MIC}=3.39 \mu \mathrm{g} / \mathrm{mL})$ and $9 \mathrm{c}(\mathrm{MIC}=2.83 \mu \mathrm{g} / \mathrm{mL})$ were 1-fold more potent than the standard drug Amoxicillin/Clavulanic acid (MIC $=6.79 \mu \mathrm{g} / \mathrm{mL}$ ). The four compounds 9a $(\mathrm{MIC}=7.1 \mu \mathrm{g} / \mathrm{mL}), 13 \mathrm{a}(\mathrm{MIC}=7.47 \mu \mathrm{g} / \mathrm{mL}), 13 \mathrm{~d}(\mathrm{MIC}=6.79 \mu \mathrm{g} / \mathrm{mL})$ and $13 \mathrm{~h}(\mathrm{MIC}=6.28 \mu \mathrm{g} / \mathrm{mL})$ were nearly equipotent to reference drug Amoxicillin/Clavulanic acid $(\mathrm{MIC}=6.79 \mu \mathrm{g} / \mathrm{mL})$.

The antifungal activity of the pyrazolo[1,5-a]pyrimidines on the Candida albicans (Ca) fungi showed that three of the pyrazolo[1,5-a]pyrimidines $(9 \mathrm{c}(\mathrm{MIC}=3.39 \mu \mathrm{g} / \mathrm{mL}), 13 \mathrm{e}(\mathrm{MIC}=3.39 \mu \mathrm{g} / \mathrm{mL})$ and $13 \mathrm{~h}(\mathrm{MIC}=2.95 \mu \mathrm{g} / \mathrm{mL}))$ were 1-fold more potent than the antifungal standard drug Nystatin $(\mathrm{MIC}=7.81 \mu \mathrm{g} / \mathrm{mL})$. Furthermore, the three compounds $5 \mathbf{c}, 9 \mathrm{a}$ and $\mathbf{1 3} \mathrm{d}$ were equipotent to the reference drug used.

On estimation of the antifungal activity on the Fusarium oxysporum (Fo) fungi, the compounds 13d $(\mathrm{MIC}=20.83 \mu \mathrm{g} / \mathrm{mL}), 13 \mathrm{e}(\mathrm{MIC}=24.79 \mu \mathrm{g} / \mathrm{mL})$ and $13 \mathrm{~h}(\mathrm{MIC}=22.88 \mu \mathrm{g} / \mathrm{mL})$ were more potent than the reference drug Nystatin (MIC $=26.4 \mu \mathrm{g} / \mathrm{mL}$ ). The two compounds $9 \mathrm{a}$ and $\mathbf{9 c}$ were nearly equipotent to the reference drug Nystatin. 
In the case of the Aspergillus brasiliensis $(\mathrm{Ab})$ fungi, the standard drug Nystatin (MIC $=20.2 \mu \mathrm{g} / \mathrm{mL}$ ) was more active than all the tested pyrazolo[1,5- $a$ ]pyrimidines (5a-c, $\mathbf{9 a}-\mathbf{c}$ and $\mathbf{1 3} \mathbf{a}-\mathbf{i})$, with their MIC ranging from $21.25 \mu \mathrm{g} / \mathrm{mL}$ to $96.15 \mu \mathrm{g} / \mathrm{mL}$.

In order to further study and conclude which of the above promising pyrazolopyrimidines compounds 5c, 9a, 9c, 13a, 13c, 13d, 13e and 13h may be bactericidal or show bacteriostatic action, the action of the compounds will be deduced from the relationship between MIC and MBC or MFC and from a comparison between the values of the compounds (Table 2). The range ratio between MIC-MBC was 1-2 ratios; antibacterial agents are generally regarded as bactericidal if the MBC is no more than four times the MIC $[32,33]$, and the values of the compounds are in this range. Therefore, the results indicated that the pyrazolopyrimidine compounds exhibited bactericidal and fungicidal properties in comparison to Amoxicillin/Clavulanic acid as an antibacterial standard and Nystatin as an antifungal standard.

\subsubsection{Immunomodulatory Activity for Active Compounds}

In this study, the immunomodulatory activity of the active pyrazolopyrimidine compounds was investigated by in vitro test. The most potent compounds depending on the previous antimicrobial results were chosen to evaluate their immunomodulatory activity for it was predicted that these compounds may have a dual function. The neutrophils play a primary role as an effecting or killer cell for many types of infections [34].

The active pyrazolopyrimidine compounds 5c, 9a, 9c, 13a, 13c, 13d, 13e and 13h were evaluated by nitroblue tetrazolium (NBT) reduction test, and the results were presented as intracellular killing percentage \% values and listed in Table 3.

Table 3. The intracellular killing activities of active pyrazolopyrimidine compounds.

\begin{tabular}{cc}
\hline Compounds & Intracellular Killing Activity \% \\
\hline $\mathbf{5 c}$ & $76.2 \pm 0.23$ \\
$\mathbf{9 a}$ & $125.6 \pm 0.44$ \\
$\mathbf{9 c}$ & $122.9 \pm 0.79$ \\
$\mathbf{1 3 a}$ & $98.7 \pm 0.61$ \\
$\mathbf{1 3} \mathbf{c}$ & $87.5 \pm 0.33$ \\
$\mathbf{1 3 d}$ & $136.3 \pm 0.16$ \\
$\mathbf{1 3 e}$ & $129.8 \pm 0.47$ \\
$\mathbf{1 3 h}$ & $117.4 \pm 0.98$ \\
\hline
\end{tabular}

The highest immunostimulatory action were $\mathbf{1 3 d}$, 13e and 9a with $136.5 \pm 0.3,129.8 \pm 0.47$ and $125.6 \pm 0.44$, respectively. In various in vitro and in vivo bioassays, Zymosan represents an efficient chemo-attractant parameter, where the nucleophile can cause microorganism intracellular killing.

From Table 3, an increase in the intracellular killing activity of neutrophils can be observed. Therefore, the effectiveness of the body's immune system may be activated by these compounds, as the neutrophils play a primary role as an effecting or killer cell for many types of infections.

\subsection{Structure-Activity Relationship (SAR)}

From the results (Table 2) of in vitro antimicrobial activities of pyrazolopyrimidine compounds 5c, 9a, 9c, 13a, 13c, 13d, 13e and 13h against the screening organisms, it was found that some pyrazolopyrmidine derivatives bearing $\mathrm{X}=\mathrm{Cl}$ (Chloro atom, electron withdrawing group) were more active than those bearing $\mathrm{X}=\mathrm{CH}_{3}$ (Methyl group, electron donating group), whereas 13h was more active than 13e. Furthermore, 9c was more active than 9a, where the derivatives bearing $\mathrm{X}=\mathrm{Cl}$ ( $\mathrm{Chloro}$ atom) were more active than those bearing $\mathrm{X}=\mathrm{H}$ (Hydrogen atom, without substitutions) against some of the screening organisms (Figure 3). 


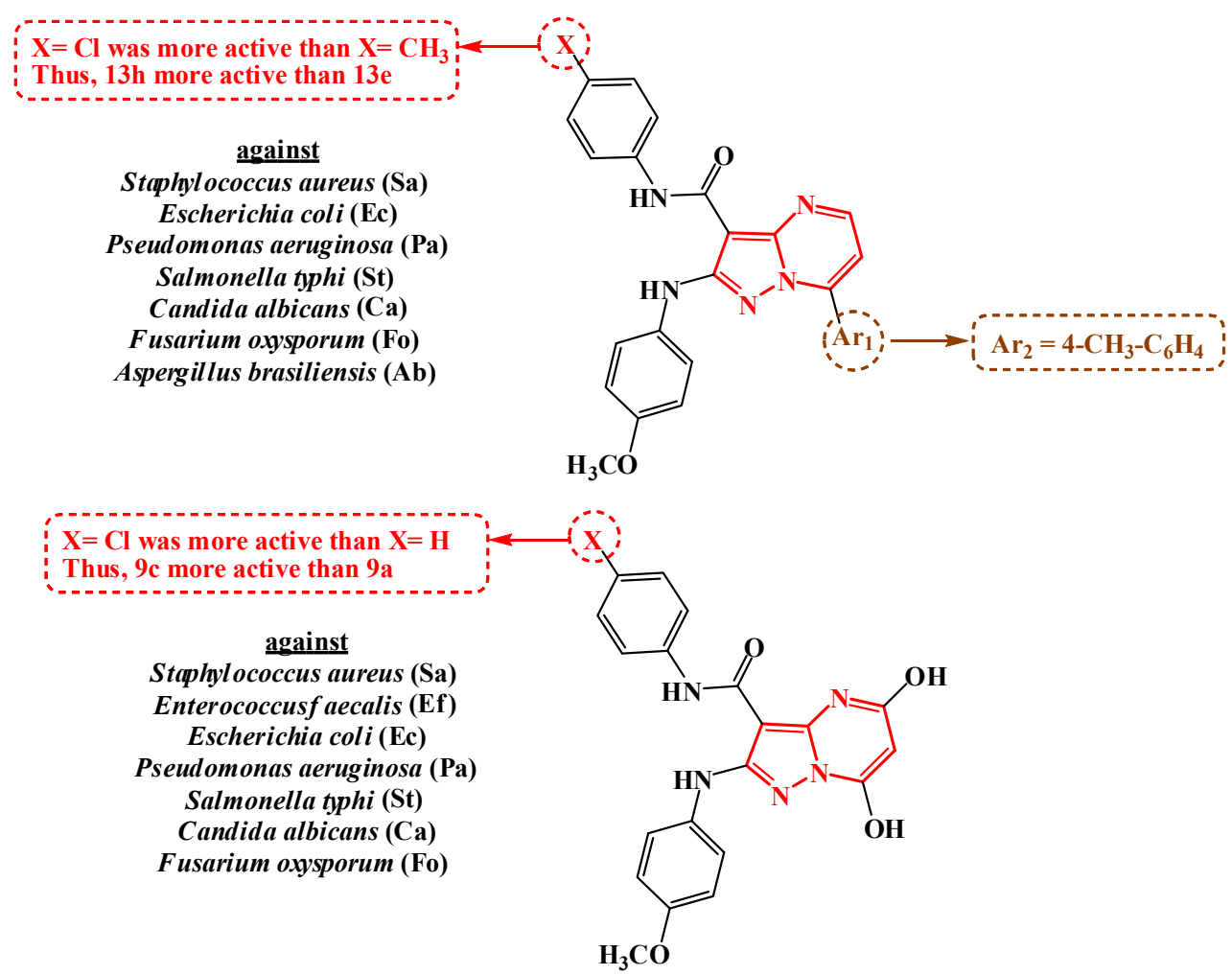

Figure 3. A brief structure-activity relationship (SAR) study of the active pyrazolopyrimidines.

2.4. Physicochemical, Pharmacokinetic, ADME, Toxicity Prediction and Drug-Likeness

2.4.1. Lipinski's Rule of Five for Pyrazolo[1,5-a]pyrimidines 5a-c, $\mathbf{9 a - c}$ and $\mathbf{1 3 a - i}$

To qualify 5,7-dimethylpyrazolo[1,5-a]pyrimidines 5a-c, 5,7-dihydroxypyrazolo[1,5-a]pyrimidines 9a-c and 7-aryl-pyrazolo[1,5-a]pyrimidine 13a-i as drug candidates, the computed molecular properties of Lipinski's rule of five were calculated using SwissADME web (http://swissadme.ch/index.php\# undefined) and are shown in Table 4.

Table 4. Lipinski's rule of five for the compounds pyrazolo[1,5-a]pyrimidines $\mathbf{5 a - c , 9 a - c}$ and $\mathbf{1 3 a}-\mathbf{i}$.

\begin{tabular}{cccccc}
\hline Compounds & $\mathbf{M W}^{\mathbf{a}}$ & $\mathbf{M L o g}^{\mathbf{b}}$ & $\boldsymbol{n} \mathbf{H B A}^{\mathbf{c}}$ & $\boldsymbol{n \mathbf { H B D } ^ { \mathbf { d } }}$ & $\mathbf{n}_{\text {violations }} \mathbf{f}^{\mathbf{f}}$ \\
\hline $\mathbf{R u l e}$ & $\mathbf{2 5 0 0}$ & $\leq \mathbf{4 . 1 5}$ & $\leq \mathbf{1 0}$ & $\leq \mathbf{5}$ & $\mathbf{0}$ \\
\hline $\mathbf{5 a}$ & 387.43 & 3.19 & 4 & 2 & 0 \\
$\mathbf{5 b}$ & 401.46 & 3.41 & 4 & 2 & 0 \\
$\mathbf{5} \mathbf{c}$ & 421.88 & 3.67 & 4 & 2 & 0 \\
$\mathbf{9 a}$ & 391.38 & 2.13 & 6 & 4 & 0 \\
$\mathbf{9 b}$ & 405.41 & 2.35 & 6 & 4 & 0 \\
$\mathbf{9 c}$ & 425.83 & 2.62 & 6 & 4 & 0 \\
$\mathbf{1 3 a}$ & 435.48 & 3.82 & 4 & 2 & 0 \\
$\mathbf{1 3 b}$ & 449.50 & 4.02 & 4 & 2 & 0 \\
$\mathbf{1 3 c}$ & 469.92 & 4.29 & 4 & 2 & 1 \\
$\mathbf{1 3 d}$ & 449.50 & 4.02 & 4 & 2 & 0 \\
$\mathbf{1 3 e}$ & 463.53 & 4.22 & 4 & 2 & 1 \\
$\mathbf{1 3 f}$ & 483.95 & 4.49 & 4 & 2 & 1 \\
$\mathbf{1 3 g}$ & 469.92 & 4.29 & 4 & 2 & 1 \\
$\mathbf{1 3 h}$ & 483.95 & 4.49 & 4 & 2 & 1 \\
$\mathbf{1 3 i}$ & 504.37 & 4.76 & 4 & 2 & 2 \\
\hline
\end{tabular}

a Molecular Weight; ${ }^{\mathrm{b}}$ Calculated Lipophilicity (MLog $P_{\mathrm{o} / \mathrm{w}}$ ); ${ }^{\mathrm{c}}$ Number of Hydrogen Bond Acceptors; ${ }^{\mathrm{d}}$ Number of Hydrogen Bond Donors; ${ }^{\mathrm{e}}$ Violations from Lipinski's Rule. 
The number of hydrogen bond acceptors and donors for all the pyrazolo[1,5-a]pyrimidines $5 \mathbf{a}-\mathbf{c}$, 9a-c and 13a-i were in accordance with Lipinski's rule of five. The molecular weight (MW) of the pyrazolo[1,5-a]pyrimidines $\mathbf{5 a - c}, \mathbf{9 a}-\mathbf{c}$ and $\mathbf{1 3} \mathbf{a}-\mathbf{i}$ were in range (less than 500, Lipinski's rule), except $13 \mathbf{i}$ which has MW $=504.37 \mathrm{~g} / \mathrm{mol}$. The lipophilicity property (MLogP $\leq 4.15$, octanol-water partition coefficient) was in the range for all the pyrazolo[1,5-a]pyrimidines $5 \mathbf{a}-\mathbf{c}, \mathbf{9 a}-\mathbf{c}$ and $\mathbf{1 3 a - i}$ excluding 13c, 13e, 13f, 13g, 13h and 13i. The highly lipophilic character (MLogP $>4.15$ ) in the range between $4.22-4.76$ of the compounds $\mathbf{1 3 c}, \mathbf{1 3 e}, \mathbf{1 3} \mathbf{f}, \mathbf{1 3} \mathrm{g}, \mathbf{1 3} \mathrm{h}$ and $\mathbf{1 3 i}$ may be because of the presence of a chloro atom in their structures [35].

\subsubsection{Pharmacokinetic Properties of Pyrazolo[1,5-a]pyrimidines 5a-c, $9 \mathbf{a}-\mathbf{c}$ and $13 \mathbf{a}-\mathbf{i}$}

The computed pharmacokinetic properties of the series of pyrazolo[1,5-a]pyrimidines $5 \mathbf{a}-\mathbf{c}$, 9a-c and 13a-i were calculated using SwissADME web (http://swissadme.ch/index.php\#undefined). The results are shown in Table S1 (see Supplementary Material).

All the compounds $\mathbf{5 a - c}, \mathbf{9 a}-\mathbf{c}$ and $\mathbf{1 3 a}-\mathbf{i}$ show high gastrointestinal absorption (GI absorption) except $\mathbf{1 3 i}$. All the compounds $\mathbf{5 a - c}, \mathbf{9 a}-\mathbf{c}$ and $\mathbf{1 3} \mathbf{a}-\mathbf{i}$ are not predicted to penetrate the blood-brain barrier (BBB) and are non-substrates for P-glycoprotein (P-gp). Therefore, they have no effect on the central nervous system.

Inhibition of the five major CYP isoforms (CYP1A2, CYP2C19, CYP2C9, CYP2D6 and CYP3A4) is certainly one major cause of pharmacokinetic-related drug-drug interactions. The compounds $\mathbf{1 3 b} \mathbf{b} \mathbf{i}$ are non-inhibitors of the CYP1A2 enzyme, the two compounds $\mathbf{9 a}$ and $\mathbf{9 b}$ are non-inhibitors of the CYP2C19 enzyme and all compounds $\mathbf{5 a}-\mathbf{c}, \mathbf{9 a}-\mathbf{c}$ and $\mathbf{1 3} \mathbf{a}-\mathbf{i}$ are inhibitors and are active against the CYP2C9 enzyme. The series $9 \mathbf{a}-\mathbf{c}$ are non-inhibitors of the CYP2D6 enzyme and compound $\mathbf{9 a}$ is a non-inhibitor of the CYP3A4 enzyme [36].

\subsubsection{In Silico ADME and Toxicity Prediction of Pyrazolo[1,5-a]pyrimidines 5a-c, 9a-c and 13a-i}

The computed in silico ADME and toxicity predictions of pyrazolo[1,5-a]pyrimidines $\mathbf{5 a - c}, \mathbf{9 a}-\mathbf{c}$ and 13a-i were calculated using the PreADMET web (https://preadmet.bmdrc.kr). The results are shown in Tables S2 and S3 (see Supplementary Material).

On the human intestinal absorption (HIA) test, all the pyrazolo[1,5-a]pyrimidines $\mathbf{5 a - c}, \mathbf{9 a}-\mathbf{c}$ and 13a-i expressed more than $70 \%$ human intestinal absorption (HIA) values, indicating good permeation across the membrane.

The results of the in vitro Caco- 2 cell permeability indicated that all pyrazolo[1,5- $a$ ]pyrimidines 5a-c, 9a-c and 13a-i exhibited moderate permeation.

On the in vitro MDCK cell permeability test, all the pyrazolo[1,5-a]pyrimidines $5 \mathbf{a}-\mathbf{c}, \mathbf{9 a}-\mathbf{c}$ and 13a-i showed permeation less than $25 \mathrm{~nm} / \mathrm{s}$, indicating low permeability.

For the in vitro skin permeability test for the delivery of drugs via transdermal administration, all the pyrazolo[1,5-a]pyrimidines $\mathbf{5 a - c}, \mathbf{9 a}-\mathbf{c}$ and $\mathbf{1 3} \mathbf{a}-\mathbf{i}$ exhibited negative values.

For the in vitro plasma protein binding (PPB) test, most of the pyrazolo[1,5-a]pyrimidines were predicted more than $90 \%$, which indicates decreased excretion and increased half-life.

On the Ames test that assesses mutagenicity, all the pyrazolo[1,5-a]pyrimidines were predicted to be mutagens. Moreover, on analyzing carcinogenicity in animals (mouse), all the compounds were predicted as positive, except compound $\mathbf{5 b}$ which presented negative, while for the carcinogenicity test in animals (rat), the compounds $\mathbf{5 c}, \mathbf{9 a}-\mathbf{c}, \mathbf{1 3} \mathbf{c}$ and $\mathbf{1 3} \mathbf{f}-\mathbf{i}$ were predicted as negative.

In the case of the hERG encodes potassium channels test, compound 9a presented high risk; 13a presented ambiguous risk and the rest of the compounds presented medium risk.

\subsubsection{Drug Likeness Calculations of Pyrazolo[1,5-a]pyrimidines 5a-c, $\mathbf{9 a}-\mathbf{c}$ and $\mathbf{1 3} \mathbf{a}-\mathbf{i}$}

Molecular polar surface area (TPSA $\left(\mathrm{A}^{2}\right)$ ) is an affected parameter in the prediction of drug transport properties. Molecular volume was calculated by using the MolSoft website (http://molsoft.com/mprop/). The percentage of absorption (\%ABS) was calculated by using $\% A B S=109-(0.345 \times$ TPSA $)$ and is 
referred to the degree of absorption [37]. The series of pyrazolo[1,5-a]pyrimidines $\mathbf{5 a}-\mathbf{c}, \mathbf{9 a}-\mathbf{c}$ and $\mathbf{1 3} \mathbf{a}-\mathbf{i}$ possessed the percentage of absorption (\%ABS) of $88.24 \%, 76.53 \%$ and $88.45 \%$, respectively.

Computed drug-likeness scores of the compounds pyrazolo[1,5-a]pyrimidines, $5 \mathbf{a}-\mathbf{c}, \mathbf{9 a}-\mathbf{c}$ and $\mathbf{1 3} \mathbf{a}-\mathbf{i}$ are presented in Table 5. Compound $\mathbf{5 b}$ has less value (DLS $=0.40$ ) but the two compounds $\mathbf{1 3} \mathbf{c}$ and $13 \mathrm{i}$ possessed a maximum drug-likeness model score of 1.31 and 1.44, respectively.

Table 5. Drug likeness calculations of the compounds pyrazolo[1,5-a]pyrimidines $\mathbf{5 a - c , ~} \mathbf{9 a}-\mathbf{c}$ and $\mathbf{1 3} \mathbf{a}-\mathbf{i}$.

\begin{tabular}{|c|c|c|c|c|}
\hline Compounds & $\operatorname{TPSA}^{a}\left(A^{2}\right)$ & Volume $^{b}\left(A^{3}\right)$ & $\% \mathrm{ABS}^{\mathrm{c}}=109-(0.345 \times$ TPSA $)$ & $\begin{array}{c}\text { Drug-Likeness } \\
\text { Model Score (DLS) }\end{array}$ \\
\hline $5 a$ & 60.18 & 379.18 & 88.24 & 0.44 \\
\hline $5 b$ & 60.18 & 400.12 & 88.24 & 0.40 \\
\hline $5 c$ & 60.18 & 396.37 & 88.24 & 1.00 \\
\hline $9 a$ & 94.13 & 358.28 & 76.53 & 0.61 \\
\hline $9 b$ & 94.13 & 379.22 & 76.53 & 0.59 \\
\hline $9 \mathrm{c}$ & 94.13 & 375.47 & 76.53 & 1.15 \\
\hline $13 a$ & 59.56 & 410.76 & 88.45 & 0.77 \\
\hline $13 b$ & 59.56 & 431.70 & 88.45 & 0.73 \\
\hline $13 c$ & 59.56 & 427.95 & 88.45 & 1.31 \\
\hline $13 d$ & 59.56 & 431.70 & 88.45 & 0.62 \\
\hline $13 e$ & 59.56 & 452.64 & 88.45 & 0.88 \\
\hline $13 \mathrm{f}$ & 59.56 & 448.89 & 88.45 & 1.25 \\
\hline $13 \mathrm{~g}$ & 59.56 & 427.95 & 88.45 & 1.20 \\
\hline $13 \mathrm{~h}$ & 59.56 & 448.89 & 88.45 & 1.25 \\
\hline $13 i$ & 59.56 & 445.14 & 88.45 & 1.44 \\
\hline
\end{tabular}

${ }^{\mathrm{a}}$ Topological polar surface area; ${ }^{\mathrm{b}}$ Molecular volume; ${ }^{\mathrm{c}}$ Percentage absorption.

\subsection{Molecular Docking}

\subsubsection{Bacteria}

There are about 30 enzymes involved in the biochemistry of the cell wall of bacteria. Antibiotics such as the penicillin series work on the inhibition of the final cross link step by inhibiting the transpeptidase enzyme. The E-score (energy score), considered as one of the most important factors, reflects the interaction between the ligand and enzyme. The molecular docking validation explains the interaction (E-score) between the reference ligand, 2-[N-cyclohexylamino]ethane sulfonic acid, (E-score $=-5.23)$ and the compounds (5c, 9a, 9c, 13a, 13c, 13d, 13e and 13h) with a transpeptidase enzyme as $-6.56,-6.47,-6.82,-6.44,-6.50,-7.17,-6.97$ and -6.87 , respectively. Furthermore, Figure 4 shows the 2D and 3D interaction diagrams of compound $13 \mathbf{d}$ with transpeptidase.

\subsubsection{Fungi}

Ergosterol biosynthesis is considered as a very important step in the building of the fungal cell membrane. 14-Alfa demethylase is the responsible enzyme that converts lanosterol to ergosterol. The molecular docking study (E-score) between the reference ligand, lanosterol, (E-score $=-8.06)$ and the synthesized compounds (5c, 9a, 9c, 13a, 13c, 13d, 13e and 13h) with 14-alpha demethylase showed figures of $-8.15,-7.40,-7.95,-7.8,-8.12,-8.54,-8.24$ and -8.17 , respectively. Figure 5 shows $2 \mathrm{D}$ and $3 \mathrm{D}$ interaction diagrams of compound $5 \mathrm{c}$ with $14-\alpha$ demethylase.

\subsubsection{Immunity Docking}

Nitro blue tetrazolium (NBT) is an organic salt compound purchased as the chloride salt based on two tetrazole moieties. These moieties have sensitivity to alkaline phosphatase (ALP) enzyme and therefore are used as a test in immunology to detect the reactivity of organic compounds on the immunity system. ALP enzyme is an ahomodimeric metalloenzyme promoting the unspecified hydrolysis of the phosphate monoesters process. This enzymatic promotion proceeds by a phosphoseryl intermediate to give inorganic phosphate and an alcohol. ALP enzyme structure as a phosphate has 
been determined by X-ray technique [38]. The inhibition of ALP presents a unique challenge since the active site pocket is characteristically shallow and, in continuation of our work [39-41] to discover new drug enzyme interactions, we present this calculated part.

The active site analysis of the ALP protein was performed from a database of similar amino acid residues (Glu411, Arg166, His331, Asp269, Lys328, Asn263, Asp153, Asp327, His412, Ser102, Gly150, Asp51, His370 and Tyr169). The 2D pocket in the alkaline phosphatase (ALP) complex with 13e as a ligand explained that the interaction between them is potent through hydrogen bonds. Furthermore, Figure 6 presents the 2D the interaction between $13 \mathbf{e}$ as a ligand with alkaline phosphatase (ALP) residues.

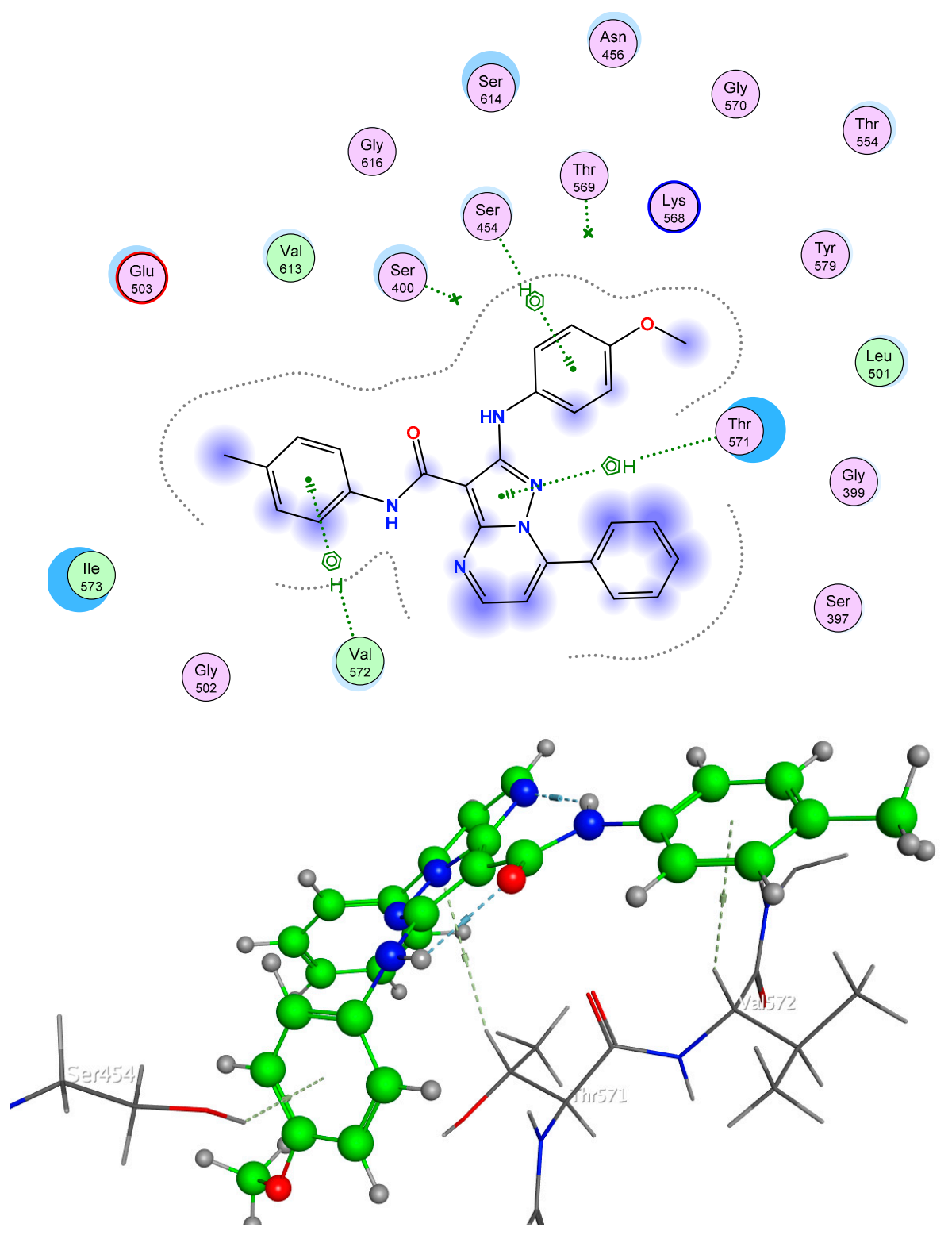

Figure 4. 2D and 3D interaction diagrams of compound 13d with transpeptidase. 


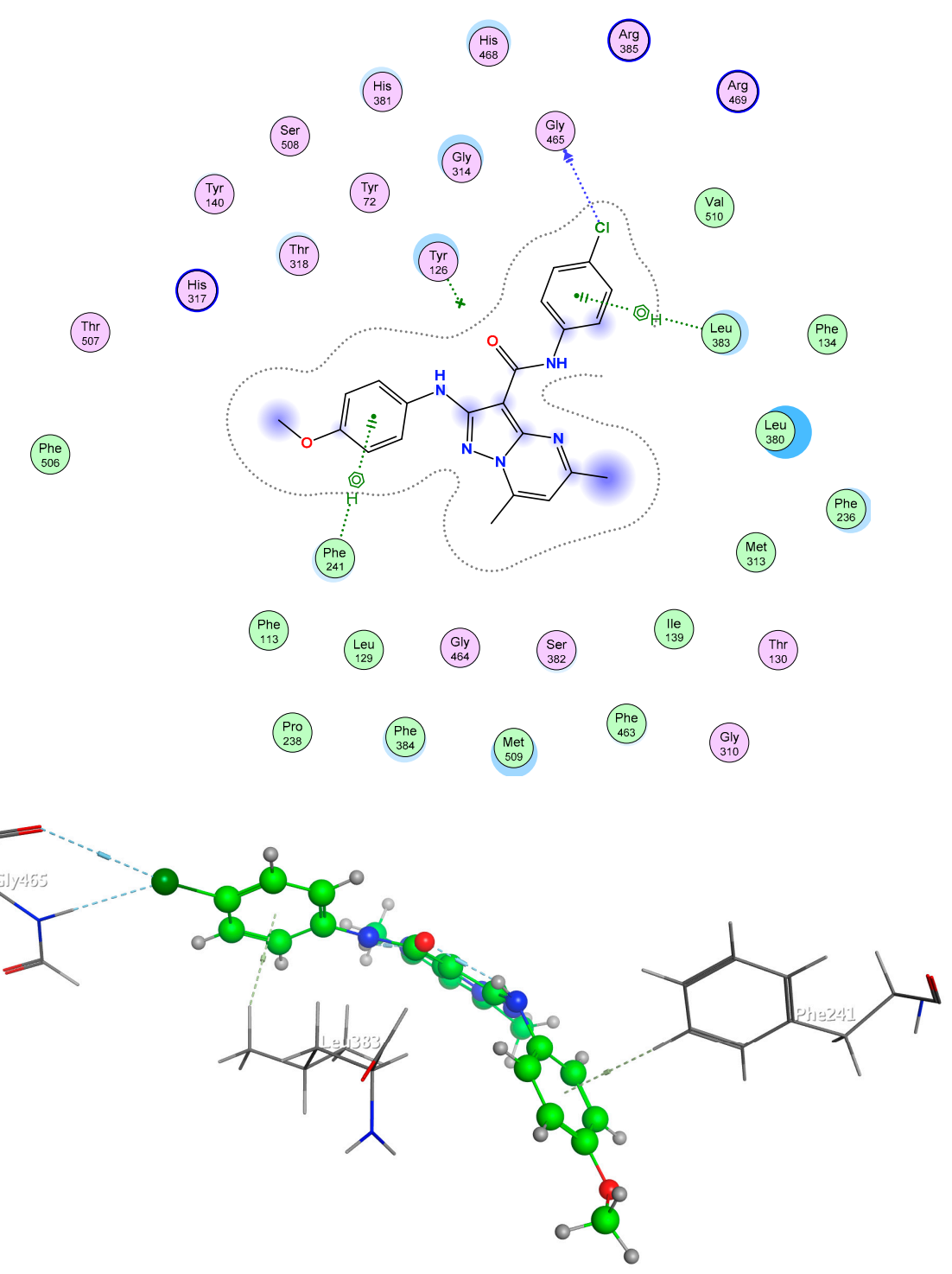

Figure 5. 2D and 3D interaction diagrams of compound 5c with 14- $\alpha$ demethylase.

Asp

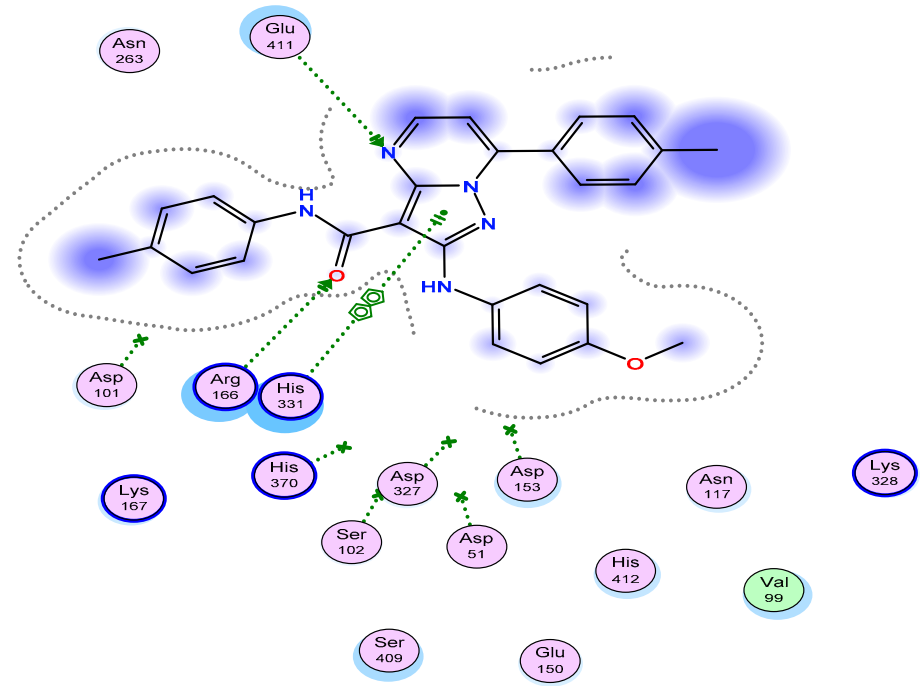

Figure 6. 2D interaction diagrams of compound $13 \mathbf{e}$ with alkaline phosphatase (ALP). 


\subsubsection{Pharmacophore and Electrostatic Map of 13e}

The selection of pyrazolopyrimidine scaffold analogs $(\mathbf{5 a}-\mathbf{c}, \mathbf{9 a}-\mathbf{c}, \mathbf{1 3} \mathbf{a}-\mathbf{i})$ to build a pharmacophore for potential alkaline phosphatase (ALP) inhibitors was based on the high potency superposition of 13e that generated a pharmacophore with H-bond acceptors (Acc, Acc2), with H-bond donor projection (Don), an aromatic center (Aro) and which was hydrophobic (hyd) (Figure 7). The electrostatic map of compound 13e shows the hydrophilic section as a violet color and the lipophilic part as a blue color (Figure 8).

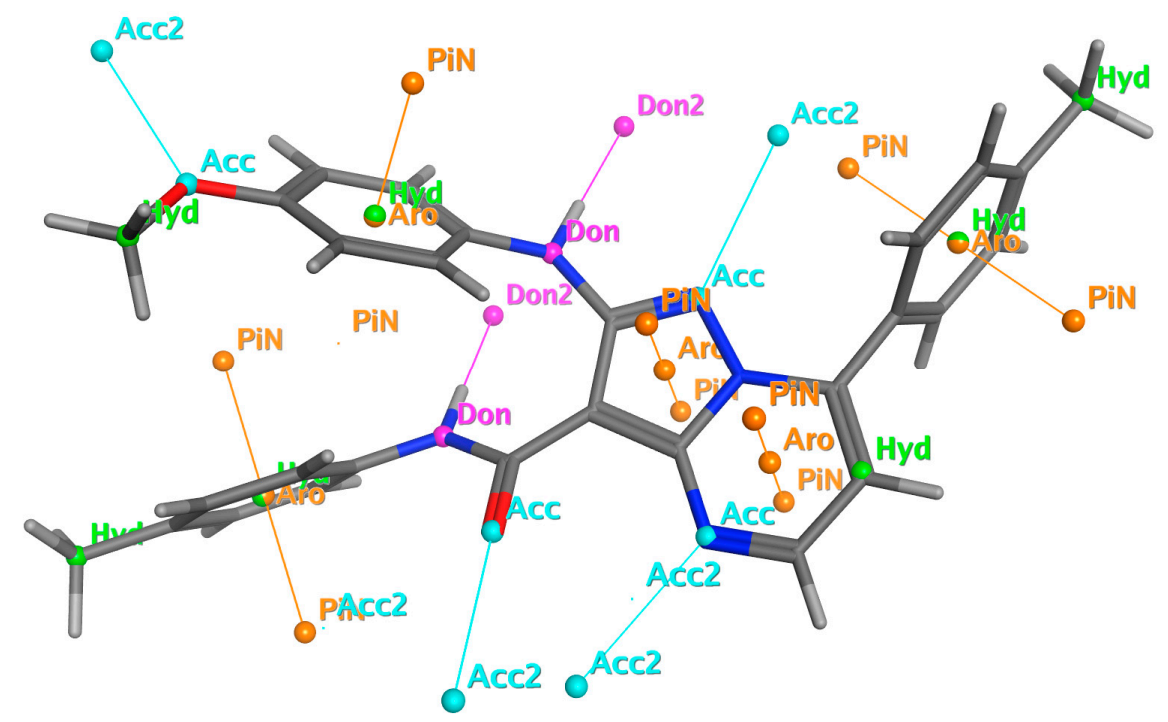

Figure 7. 3D pharmacophore structure of $\mathbf{1 3 e}$ simulated to an active site in alkaline phosphatase (ALP).

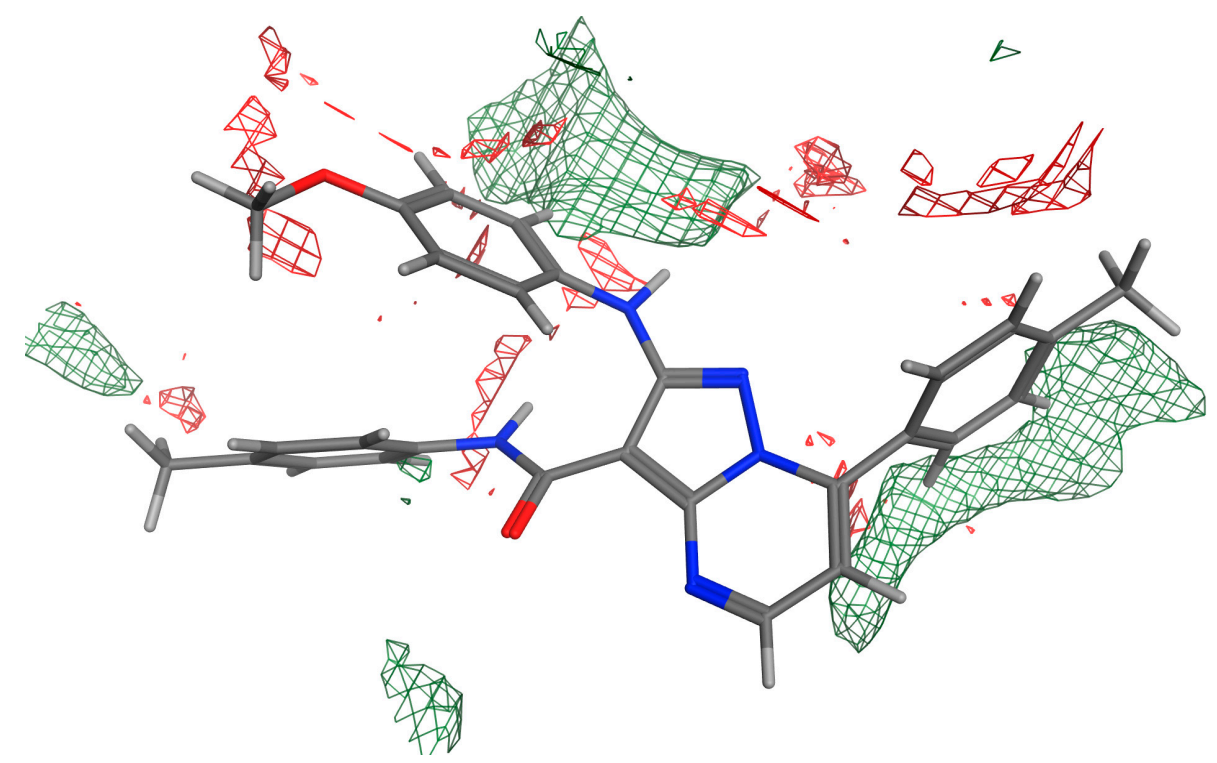

Figure 8. The electrostatic map of $\mathbf{1 3 e}$ shows the hydrophilic part (violet color) and the lipophilic part (blue color).

\section{Materials and Methods}

\subsection{Chemicals}

N-Aryl-2-[(4-methoxyphenyl)amino]-5,7-dimethylpyrazolo[1,5-a]-pyrimidine-3-carboxamides 5a-c [42], $N$-aryl-5,7-dihydroxy-2-(4-methoxyphenylamino)pyrazolo[1,5-a]pyrimidine-3-carboxamides 
9a-c [43] and 7-aryl-2-(arylamino)pyrazolo[1,5-a]pyrimidine-3-carboxamides 13a-i [44] were prepared according to the reported procedure.

The chemical structures of 5a-c [42], 9a-c [43] and 13a-i [44] were confirmed via spectral data (see Supplementary Material).

\subsection{In Vitro Biological Evaluation}

The test microorganisms used in this study were: Gram-positive bacteria: Bacillus cereus (ATCC14579, Bc), Staphylococcus aureus (ATCC 29213, Sa) and Enterococcus faecalis (ATCC 29212, Ef). Gram-negative bacteria: Escherichia coli (ATCC 25922, Ec), Pseudomonas aeruginosa (ATCC 27853, Pa) and Salmonella typhi (ATCC 6539, St). Fungi: Candida albicans (ATCC 10231, Ca), Fusarium oxysporum (RCMB 008002, Fo) and Aspergillus brasiliensis (ATCC 16404, Ab).

The antimicrobial activities inhibition zone (IZ, $\mathrm{mm} \pm$ standard deviation) was measured according to the agar plate diffusion method $[27,28]$ (see Supplementary Material).

The MIC, MBC and MFC of the potent pyrazolo[1,5-a]pyrimidines: The minimum inhibitory concentration (MIC), the minimum bactericidal concentration $(\mathrm{MBC}, \mu \mathrm{g} / \mathrm{mL}$ ) and the minimum fungicidal concentration (MFC, $\mu \mathrm{g} / \mathrm{mL})$ of the most potent pyrazolo[1,5-a]pyrimidines $(5 \mathbf{c}, 9 \mathbf{a}, 9 \mathbf{c}$, 13a, 13c, 13d, 13e and 13h) were determined by the conventional technique termed paper disk diffusion [29-31] (see Supplementary Material).

The immunomodulatory activity of the potent pyrazolo[1,5-a]pyrimidines compounds $5 \mathbf{c}, 9 \mathbf{a}, 9 \mathbf{c}$, 13a, 13c, 13d, 13e and $\mathbf{1 3}$ h was evaluated by nitroblue tetrazolium (NBT) reduction test $[45,46]$ (see Supplementary Material).

\subsection{Molecular Docking}

The standard docking protocol was carried out using MOE 2015.10 software. The proteins in the mdb file downloaded from the PDB (protein data bank) were transpeptidase (PDB code: 4ZTK), 14-alpha demethylase (PDB code: 4LXJ) and alkaline phosphatase ALP (PDB code: 1EW8) (http://www.rcsb.org/pdb/home/home.do).

\section{Conclusions}

In this work, a series of pyrazolo[1,5-a]pyrimidine derivatives $\mathbf{5 a - c}, \mathbf{9 a}-\mathbf{c}$ and $\mathbf{1 3 a - i}$ were synthesized for evaluation of their in vitro antimicrobial and immunomodulatory activities. The result of pyrazolo[1,5-a]pyrimidines exhibited that most of the compounds displayed significant antimicrobial (bactericidal and fungicidal properties) and immunomodulatory activities. Furthermore, the in silico predicted physicochemical, pharmacokinetic, ADMET properties and drug-likeness studies of the pyrazolo[1,5-a]pyrimidines $\mathbf{5 a - c}, \mathbf{9 a}-\mathbf{c}$ and $\mathbf{1 3 a}-\mathbf{i}$ revealed that the compounds fulfill Lipinski's rule requirements and have good drug score values, particularly in $13 \mathbf{c}(\mathrm{DLS}=1.31$ ) and $13 \mathbf{i}$ (DLS $=1.44)$. Furthermore, the molecular docking study was compatible with antimicrobial and immunomodulatory activities. These preliminary results of pyrazolo[1,5-a]pyrimidines as antimicrobial activities and the structure-activity relationship with molecular docking could provide an exceptional model that may lead to the discovery of new drugs.

Supplementary Materials: The following are available online, Tables S1-S3, Spectral data of compounds (1a-c, $5 \mathbf{a}-\mathbf{c}, 9 \mathbf{a}-\mathbf{c}$ and $13 \mathbf{a}-\mathbf{i})$ and biological methods are available online.

Author Contributions: A.S.H. formulated the research idea; A.S.H., A.M.N., M.A.A.-O. and M.A.B. carried out the experiments and interpreted the data; A.A.A. performed the antimicrobial and immunomodulatory evaluation; T.K.K. performed the molecular docking. All authors have read and agreed to the published version of the manuscript.

Funding: The authors would like to extend their sincere appreciation to the Deanship of Scientific Research at King Saud University for its funding of this research through the Research Group No.: RG-1436-015.

Conflicts of Interest: The authors declare no conflicts of interest. 


\section{References}

1. Shaaban, O.G.; Issa, D.A.E.; El-Tombary, A.A.; Abd El Wahab, S.M.; Abdel Wahab, A.E.; Abdelwahab, I.A. Synthesis and molecular docking study of some 3,4-dihydrothieno[2,3-d]pyrimidine derivatives as potential antimicrobial agents. Bioorg. Chem. 2019, 88, 102934. [CrossRef] [PubMed]

2. Chobe, S.S.; Dawane, B.S.; Tumbi, K.M.; Nandekar, P.P.; Sangamwar, A.T. An ecofriendly synthesis and DNA binding interaction study of some pyrazolo[1,5-a]pyrimidines derivatives. Bioorg. Med. Chem. Lett. 2012, 22, 7566-7572. [CrossRef] [PubMed]

3. Modi, P.; Patel, S.; Mahesh, C. Structure-based design, synthesis and biological evaluation of a newer series of pyrazolo[1,5-a]pyrimidine analogues as potential anti-tubercular agents. Bioorg. Chem. 2019, 87, $240-251$. [CrossRef] [PubMed]

4. El-Mekabaty, A.; Fadda, A.A. Novel pyrazolo[1,5- $a$ ]pyrimidines and pyrazolo[5,1-c][1,2,4]triazines incorporating indole moiety as a new class of antioxidant agents. J. Heterocycl. Chem. 2018, 55, 2303-2308. [CrossRef]

5. Hassan, A.S.; Moustafa, G.O.; Askar, A.A.; Naglah, A.M.; Al-Omar, M.A. Synthesis and antibacterial evaluation of fused pyrazoles and Schiff bases. Synth. Commun. 2018, 48, 2761-2772. [CrossRef]

6. Hassan, A.S.; Hafez, T.S.; Osman, S.A.M.; Ali, M.M. Synthesis and in vitro cytotoxic activity of novel pyrazolo[1,5-a]pyrimidines and related Schiff bases. Turk. J. Chem. 2015, 39, 1102-1113. [CrossRef]

7. Hafez, T.S.; Osman, S.A.; Yosef, H.A.A.; Abd El-All, A.S.; Hassan, A.S.; El-Sawy, A.A.; Abdallah, M.M.; Youns, M. Synthesis, structural elucidation and in vitro antitumor activities of some pyrazolopyrimidines and Schiff bases derived from 5-amino-3-(arylamino)-1H-pyrazole-4-carboxamides. Sci. Pharm. 2013, 81, 339-357. [CrossRef]

8. Hassan, A.S.; Moustafa, G.O.; Awad, H.M. Synthesis and in vitro anticancer activity of pyrazolo[1,5-a] pyrimidines and pyrazolo[3,4-d][1,2,3]triazines. Synth. Commun. 2017, 47, 1963-1972. [CrossRef]

9. Dawane, B.S.; Konda, S.G.; Zangade, S.B. Design, Synthesis and Characterization of Some Novel Pyrazolo[1,5-a] pyrimidines as Potent Antimicrobial Agents. J. Heterocycl. Chem. 2010, 47, 1250-1254. [CrossRef]

10. Hassan, A.S.; Masoud, D.M.; Sroor, F.M.; Askar, A.A. Synthesis and biological evaluation of pyrazolo[1,5-a]pyrimidine-3-carboxamide as antimicrobial agents. Med. Chem. Res. 2017, 26, 2909-2919. [CrossRef]

11. Bondock, S.; Rabie, R.; Etman, H.A.; Fadda, A.A. Synthesis and antimicrobial activity of some new heterocycles incorporating antipyrine moiety. Eur. J. Med. Chem. 2008, 43, 2122-2129. [CrossRef] [PubMed]

12. Parry, D.; Guzi, T.; Shanahan, F.; Davis, N.; Prabhavalkar, D.; Wiswell, D.; Seghezzi, W.; Paruch, K.; Dwyer, M.P.; Doll, R.; et al. Dinaciclib (SCH 727965), a novel and potent cyclin-dependent kinase inhibitor. Mol. Cancer Ther. 2010, 9, 2344-2353. [CrossRef] [PubMed]

13. Bose, P.; Simmons, G.L.; Grant, S. Cyclin-dependent kinase inhibitor therapy for hematologic malignancies. Expert Opin. Investig. Drugs 2013, 22, 723-738. [CrossRef] [PubMed]

14. Hassan, A.S.; Askar, A.A.; Nossier, E.S.; Naglah, A.M.; Moustafa, G.O.; Al-Omar, M.A. Antibacterial Evaluation, In Silico Characters and Molecular docking of Schiff Bases Derived from 5-aminopyrazoles. Molecules 2019, 24, 3130. [CrossRef]

15. Magd-El-Din, A.A.; Mousa, H.A.; Labib, A.A.; Hassan, A.S.; Abd El-All, A.S.; Ali, M.M.; El-Rashedy, A.A.; El-Desoky, A.H. Benzimidazole-Schiff bases and their complexes: Synthesis, anticancer activity and molecular modeling as Aurora kinase inhibitor. Z. Nat. C 2018, 73, 465-478. [CrossRef]

16. Khatab, T.K.; Abdelghany, A.M.; Soliman, H.A. $\mathrm{V}_{2} \mathrm{O}_{5}$ based quadruple nano-perovskite as a new catalystfor the synthesis of bis and tetrakis heterocyclic compounds. Appl. Organomet. Chem. 2019, 33, e4783. [CrossRef]

17. Hassan, A.S.; Hafez, T.S. Antimicrobial Activities of Ferrocenyl Complexes: A Review. J. App. Pharm. Sci. 2018, 8, 156-165.

18. Hassan, A.S.; Awad, H.M.; Magd-El-Din, A.A.; Hafez, T.S. Synthesis and in vitro antitumor evaluation of novel Schiff bases. Med. Chem. Res. 2018, 27, 915-927. [CrossRef]

19. Hassan, A.S.; Hafez, T.S.; Ali, M.M.; Khatab, T.K. Design, synthesis and cytotoxic activity of some new pyrazolines bearing benzofuran and pyrazole moieties. Res. J. Pharm. Biol. Chem. Sci. 2016, 7, 417-429. 
20. Abd El-All, A.S.; Hassan, A.S.; Osman, S.A.; Yosef, H.A.A.; Abdel-Hady, W.H.; El-Hashash, M.A.; Atta-Allah, S.R.; Ali, M.M.; El Rashedy, A.A. Synthesis, characterization and biological evaluation of new fused triazine derivatives based on 6-methyl-3-thioxo-1,2,4-triazin-5-one. Acta Pol. Pharm. 2016, 73, 79-92.

21. Hassan, A.S.; Osman, S.A.; Hafez, T.S. 5-Phenyl-2-furaldehyde: Synthesis, Reactions and Biological Activities. Egypt. J. Chem. 2015, 58, 113-139.

22. Osman, S.A.; Mousa, H.A.; Yosef, H.A.A.; Hafez, T.S.; El-Sawy, A.A.; Abdallah, M.M.; Hassan, A.S. Synthesis, characterization and cytotoxicity of mixed ligand $\mathrm{Mn}(\mathrm{II}), \mathrm{Co}(\mathrm{II})$ and $\mathrm{Ni}(\mathrm{II})$ complexes. J. Serb. Chem. Soc. 2014, 79, 953-964. [CrossRef]

23. Osman, S.A.; Yosef, H.A.A.; Hafez, T.S.; El-Sawy, A.A.; Mousa, H.A.; Hassan, A.S. Synthesis and antibacterial activity of some novel chalcones, pyrazoline and 3-cyanopyridine derivatives based on khellinone as well as $\mathrm{Ni}(\mathrm{II}), \mathrm{Co}(\mathrm{II})$ and Zn(II) complexes. Aust. J. Basic Appl. Sci. 2012, 6, 852-863.

24. Elgemeie, G.H.; Elsayed, S.H.; Hassan, A.S. Design and synthesis of the first thiophene thioglycosides. Synth. Commun. 2009, 39, 1781-1792. [CrossRef]

25. Elgemeie, G.H.; Elsayed, S.H.; Hassan, A.S. Direct route to a new class of acrylamide thioglycosides and their conversions to pyrazole derivatives. Synth. Commun. 2008, 38, 2700-2706. [CrossRef]

26. Khatab, T.K.; Hassan, A.S.; Hafez, T.S. $\mathrm{V}_{2} \mathrm{O}_{5} / \mathrm{SiO}_{2}$ as an efficient catalyst in the synthesis of 5-aminopyrazole derivatives under solvent free condition. Bull. Chem. Soc. Ethiop. 2019, 33, 135-142. [CrossRef]

27. Cappuccino, J.G.; Sherman, N. Microbiology, Laboratory Manual; Pearson Education, Inc.: New Delhi, India, 2004; pp. 282-283.

28. El-sherbiny, G.M.; El-Batal, A.I.; El-Sherbiny, I.M.; Askar, A.A. Antibacterial Potential with Molecular Docking Study against Multi-Drug Resistant Bacteria and Mycobacterium tuberculosis of Streptomycin Produced by Streptomyces atroverins, strain Askar-SH50. J. Chem. Pharm. Res. 2017, 9, 189-208.

29. Cooper, K. The theory of antibiotic inhibition zones. In Analytical Microbiology; Academic Press: New York, NY, USA; London, UK, 1963; pp. 1-85.

30. El-Batal, A.I.; El-Sayed, M.H.; Refaat, B.M.; Askar, A.A. Marine Streptomyces cyaneus Strain Alex-SK121 Mediated Eco-friendly Marine Streptomyces cyaneus Strain Alex-SK121 Mediated Eco-friendly Synthesis of Silver Nanoparticles Using Gamma Radiation. Br. J. Pharm. Res. 2014, 4, 2525-2547.

31. Ghorab, M.M.; Soliman, A.M.; Alsaid, M.S.; Askar, A.A. Synthesis, antimicrobial activity and docking study of some novel 4-(4,4-dimethyl-2,6 dioxocyclohexylidene) methylamino derivatives carrying biologically active sulfonamide moiety. Arab. J. Chem. 2020, 13, 545-556. [CrossRef]

32. Sun, N.; Li, M.; Cai, S.; Li, Y.; Chen, C.; Zheng, Y.; Li, X.; Fang, Z.; Lv, H.; Lu, Y.J. Antibacterial evaluation and mode of action study of BIMQ, a novel bacterial cell division inhibitor. Biochem. Biophys. Res. Commun. 2019, 514, 1224-1230. [CrossRef]

33. Kusakabe, Y.; Mizutani, S.; Kamo, S.; Yoshimoto, T.; Tomoshige, S.; Kawasaki, T.; Takasawa, R.; Tsubaki, K.; Kuramochi, K. Synthesis, antibacterial and cytotoxic evaluation of flavipucine and its derivatives. Bioorg. Med. Chem. Lett. 2019, 29, 1390-1394. [CrossRef] [PubMed]

34. Akbay, P.; Basaran, A.A.; Undeger, U.; Basaran, N. In vitro immunomodulatory activity of flavonoid glycosides from Urtica dioica L. Phytother. Res. 2003, 17, 34-37. [CrossRef]

35. Lipinski, C.A.; Lombardo, F.; Dominy, B.W.; Feeney, P.J. Experimental and computational approaches to estimate solubility in drug discovery and development settings. Adv. Drug Deliv. Rev. 2001, 46, 3-26. [CrossRef]

36. Daina, A.; Michielin, O.; Zoete, V. SwissADME: A free web tool to evaluate pharmacokinetics, drug-likeness and medicinal chemistry friendliness of small molecules. Sci. Rep. 2017, 7, 42717. [CrossRef] [PubMed]

37. Desai, N.C.; Kotadiya, G.M.; Trivedi, A.R. Studies on molecular properties prediction, antitubercular and antimicrobial activities of novel quinoline based pyrimidine motifs. Bioorg. Med. Chem. Lett. 2014, 24, 3126-3130. [CrossRef] [PubMed]

38. Holtz, K.M.; Stec, B.; Myers, J.K.; Antonelli, S.M.; Widlanski, T.S.; Kantrowitz, E.R. Alternate modes of binding in two crystal structures of alkaline phosphatase-inhibitor complexes. Protein Sci. 2000, 9, 907-915. [CrossRef] [PubMed]

39. Soliman, H.A.; Khatab, T.K. New approach for tetrachlorosilane promoted one pot, condensation reaction for tetrahydrobenzo[a]xanthene-11-ones with docking validation as aurora kinase inhibitor. Silicon 2018, 10, 229-233. [CrossRef] 
40. Khatab, T.K.; Mubarak, A.Y.; Soliman, H.A. Design and Synthesis Pairing Between Xanthene and Tetrazole in Pentacyclic System Using Tetrachlorosilane with Aurora Kinase Inhibitor Validation. J. Heterocycl. Chem. 2017, 54, 2463-2470. [CrossRef]

41. Soliman, H.A.; Khatab, T.K.; Abdel-Megeid, F.M.E. Utilization of bromine azide access to vicinal-azidobromides from arylidene malononitrile. Chin. Chem. Lett. 2016, 27, 1515-1518. [CrossRef]

42. Hassan, A.S.; Hafez, T.S.; Osman, S.A. Synthesis, characterization, and cytotoxicity of some new 5-aminopyrazole and pyrazolo[1,5-a]pyrimidine derivatives. Sci. Pharm. 2015, 83, 27-39. [CrossRef]

43. Hassan, A.S.; Mady, M.F.; Awad, H.M.; Hafez, T.S. Synthesis and antitumor activity of some new pyrazolo[1,5-a]pyrimidines. Chin. Chem. Lett. 2017, 28, 388-393. [CrossRef]

44. El-Naggar, M.; Hassan, A.S.; Awad, H.M.; Mady, M.F. Design, synthesis and antitumor evaluation of novel pyrazolopyrimidines and pyrazoloquinazolines. Molecules 2018, 23, 1249. [CrossRef] [PubMed]

45. Ferrante, A.; Thong, Y.H. Optimal conditions for simultaneous purification of mononuclear and polymorphonuclear leucocytes from human blood by the Hypaque-Ficoll method. J. Immunol. Methods 1980, 36, 109-117. [CrossRef]

46. Baehner, R.L.; Nathan, D.G. Quantitative nitroblue tetrazolium test in chronic granulomatous disease. N. Engl. J. Med. 1968, 278, 971-976. [CrossRef] [PubMed]

Sample Availability: Samples of the compounds are not available from the authors. 